\title{
DISCURSO AMBIENTAL E A APROPRIAÇÃO DA NATUREZA: O CASO DO COMPLEXO INDUSTRIAL PORTUÁRIO DE SUAPE - PERNAMBUCO - BRASIL
}

\author{
ENVIRONMENTAL DISCOURSE AND APPROPRIATION \\ OF THE NATURE: THE CASE OF SUAPE INDUSTRIAL \\ COMPLEX PORT - PERNAMBUCO - BRASIL \\ DISCURSO AMBIENTAL Y LA APROPIACIÓN DE LA \\ NATURALEZA: EL CASO DEL COMPLEJO INDUSTRIAL \\ PORTUARIO DE SUAPE - PERNAMBUCO - BRASIL
}
Dweison Nunes Souza da Silva - Universidade Federal de Pernambuco - Pernambuco - Recife - Brasil dweison@gmail.com

Edvânia Torres Aguiar Gomes - Universidade Federal de Pernambuco - Pernambuco - Recife - Brasil torres@ufpe.br

\section{Resumo}

Na contemporaneidade, a questão ambiental está na ordem do dia de muitas corporações, sejam públicas, privadas ou "parceiras" - o que é mais comum, mesmo não sendo oficialmente. Aparentemente compartilham objetivos convergentes: suas atividades intimamente correlacionadas a imperativos socioambientais, pelo menos no discurso. Nesse sentido, este artigo busca analisar a efetividade do discurso socioambiental promovido pelo Complexo Industrial Portuário de Suape - papel do Estado, enquanto políticas públicas ambientais, acerca da conservação/ preservação das Unidades de Conservação e Áreas de Preservação Permanente. Para tanto, são revisitados e abordados, dialeticamente, referenciais teórico-metodológicos e publicações oficiais por meio de pesquisa documental/ bibliográfica. Observa-se que o discurso ambiental se apresenta contraditório, uma vez que o CIPS aparentemente apresenta suas atividades regradas por políticas públicas aliadas à sustentabilidade; todavia, historicamente, atua também num contexto de legitimação através de políticas públicas e de atividades estritamente econômicas, inserido, pois, numa lógica de exploração e apropriação dessa natureza que teoricamente se almejaria preservar.

Palavras-chave: Suape, discurso ambiental, políticas públicas, conservação/ preservação.

\begin{abstract}
In contemporary times, the environmental matter is on the agenda of many corporations, whether public, private or "partners"- which is more common, even though it is not officially. They apparently share convergent goals: their activities closely correlated with socio-environmental imperatives, at least in discourse. In this sense, this essay seeks to analyze the effectiveness of the social environmental discourse promoted by Suape Port Industrial Complex - the role of the State, where as environmental public policies - about the conservation / preservation of Conservation Units and Permanent Preservation Areas. Therefore, To this end, theoretical and methodological references and official publications are reviewed and approached through documental / bibliographic research. It is observed that the environmental discourse presents contradictory, since the CIPS apparently presents its activities governed by public policies allied to sustainability; nevertheless, historically, it also acts in a context of legitimation through public policies and strictly economic activities, inserted, therefore, in a logic of exploration and appropriation of this nature that it theoretically seeks to preserve. Keywords: Suape, environmental discourse, public policy, conservation / preservation.
\end{abstract}




\section{Resumen}

En la contemporaneidad la cuestión ambiental está a la orden del día de muchas corporaciones, sean públicas, privadas o mixtas - lo que es más común, auque no sea oficialmente. Aparentemente comparten objetivos convergentes: tienen sus actividades íntimamente correlacionadas a imperativos socioambientales, por lo menos en el discurso. En este sentido, este ensayo busca analizar la efectividad del discurso socioambiental del Complexo Industrial Portuario Suape - el papel del Estado, respecto a políticas públicas (ambientales) - acerca de la conservación/ preservación de las Unidades de Conservación y Áreas de Preservación Permanente. Para ello, se revisan dialécticamente algunos referenciales teórico-metodológicos y publicaciones oficiales por medio de una investigación documental/ bibliográfica. Se observa que el discurso ambiental se presenta contradictorio en la medida en que el CIPS, aparentemente, tiene sus actividades reglamentadas por las políticas públicas de desarrollo asociadas a la sustentabilidad; sin embrago históricamente ha actuado en un contexto de legitimación - también a través de políticas públicas - de actividades estrictamente económicas, por tanto, interviniendo en una lógica de explotación y de apropiación de esa naturaleza que teóricamente se pretende preservar.

Palabras clave: Suape, discurso ambiental, políticas públicas, conservación/ preservación.

\section{Introdução}

Na contemporaneidade, a questão ambiental está na ordem do dia de muitas corporações, sejam públicas, privadas ou "parceiras". Pois o mais comum é que, mesmo não sendo oficialmente, aparentemente compartilham objetivos convergentes: têm suas atividades intimamente correlacionadas a imperativos socioambientais, pelo menos no discurso. O Complexo Industrial Portuário de Suape, doravante CIPS, é em grande medida um exemplo disso. A empresa, especialmente na figura do Estado e também das organizações privadas que ali atuam, estampa em sua página virtual os três pilares da sustentabilidade em que está apoiada: o social, o econômico e o ambiental, com a condição de que eles "coexistam e interajam, colaborando com o crescimento econômico de Pernambuco" (Disponível em: <http://www.suape.pe.gov.br/pt/meio-ambiente/ desenvolvimento-com-sustentabilidade $>$ ).

Nesse sentido, o Estado como "mediador" por meio das políticas públicas ambientais do discurso ambiental ${ }^{1}$ contemporâneo, com vistas, sobretudo, à conservação/preservação dos ambientes face às degradações impostas pelo modelo de desenvolvimento da atual sociedade capitalista, convive aparentemente, conforme a visão de Lessa (2013), como um paradoxo na medida em que sua função (fundante e atual) é estar tão somente a serviço de uma classe dominante. Segundo as palavras do pesquisador, o Estado tem, em "seu solo fundante, a reprodução material da sociedade, a economia” (Lessa, 2013, p. 182), ou ainda, continua sendo "o comitê que administra os negócios comuns de toda a classe 
burguesa” (Lessa, 2013, p. 186), configurando-se como o executivo da classe dominante. Em adição, Paniago (2005) afirma que desde a sua gênese até a contemporaneidade, esse Estado vem se metamorfoseando, sem, contudo, retirar-se do seu aspecto primordial, que é tão somente tornar uma classe economicamente dominante e, também, politicamente dominante, exercendo, portanto, o "seu papel de facilitador da acumulação e expansão do capital” (Paniago, 2005, p. 09).

Nada obstante, o "compromisso" ambiental contemporâneo, especialmente regido pelo Estado através de suas políticas públicas, pressupõe ambientes que, a depender de suas particularidades, adquirem status de proteção - no sentido de conservar e/ou preservar, sendo, notadamente, este pensar moderno justificado face às degradações ambientais impostas pela sociedade de modus operandi capitalista (Santos et al., 2012). Em razão disso, a finalidade das políticas públicas ambientais seria, fundamentalmente, conceber à presente e às gerações futuras algo "sólido e duradouro".

O Estado tornar-se-ia "o Estado de bem estar socioambiental”, logo, concebendo a possibilidade real de conservação/preservação dos ambientes por meio de políticas públicas socioambientais. Essa assertiva, aparentemente, é contraditória na medida em que, para esta sociedade, a classe dominante, inicialmente não existe algo "sólido e duradouro", uma vez que o aspecto basilar de sua reprodução é o constante "vir a ser", que se constitui em um processo frenético de inovação que se nos apresenta através da "destruição-renovação", que na ótica de Berman (1986, p. 108), ao comentar sobre Marx, "desmancha no ar tudo o que é sólido”. Ou seja, essa necessidade material de destruir para criar o "novo" conduz justamente a não conservação e/ou preservação da natureza via legislação ambiental com a criação de áreas protegidas, por exemplo.

Portanto, ainda que sinuosamente, se caminha com a premissa de pensar o Estado como um mediador de conflitos entre a necessidade de conservação/preservação da natureza e a reprodução (exploração) da sociedade capitalista; é, como afirma Lessa (2013), ao citar Howe (1993), tão somente "capturar o 'Zeitgeist', a mais traiçoeira das ilusões”, ou seja, em outras palavras, [...] "fazer as pessoas 'crerem' no que não existe" (Lessa, 2013, p. 183)".

Do anterior, emergem os seguintes questionamentos: até que ponto o discurso socioambiental para o caso do CIPS, na figura do 
Estado, torna-se efetivo e/ou é materializado? E ainda, estaria a questão ambiental nesse contexto sendo realmente integrada aos imperativos econômicos de contradições da atual sociedade capitalista cujas determinações estruturais, aparentemente, não permitem precisamente esta integrabilidade?

Por meio dessa ótica, esta investigação reflete sobre a atuação do Estado no contexto pelo qual a legislação supõe que seja equânime, mas, que não raramente, os técnicos terminam por defender os interesses do gestor que, por sua vez, não é político, senão um gerente de projetos. E, ainda, como os grandes empreendimentos, como o CIPS, atuam na condição de vetores imobiliários, mesmo que não declarados. Em razão disso, o presente estudo objetiva analisar a efetividade do discurso socioambiental do CIPS - papel do Estado, enquanto políticas públicas (ambientais) acerca da conservação/preservação dos ambientes, sobretudo, das Unidades de Conservação e Áreas de Preservação Permanente.

Para tanto, utiliza-se de mediações teórico-metodológicas por meio de pesquisa documental e/ou bibliográfica, de publicações oficiais em periódicos, bem como visitas de campo por meio das quais foram organizados dois capítulos e, em seguida, finalizando com as considerações finais. O primeiro capítulo retrata o papel das políticas públicas promovidas pelo Estado para o CIPS e de sua função no contexto globalizado da economia. No segundo, presta-se esforços para refletir sobre a perspectiva (de)integrativa socioambiental contemporânea entre Capital, Estado e Natureza, especialmente na ótica materialista, segundo os autores István Mészáros (2011), Maria Cristina Paniago (2005), Sergio Lessa (2013), enfatizando as leis que tratam de Áreas de Preservação Permanente (APP) e Unidades de Conservação (UC) contextualizadas às políticas públicas de uso e ocupação nesses ambientes no território de Suape historicamente. Por fim, reitera-se nas considerações finais (em termos reflexivos e de advertência) os desafios e as perspectivas à materialidade dos imperativos socioambientais contemporâneos.

\section{Suape: Caminhos não tão Sinuosos na Contemporaneidade}

O CIPS está situado na Nucleação Sul da Região Metropolitana do Recife, distante cerca de 40 quilômetros de Recife, localizado entre os municípios do Cabo de Santo Agostinho e de Ipojuca, com acesso a partir 
da BR-101 e da PE-60, com área territorial de aproximadamente 13,5 mil $\mathrm{km}^{2}$ (CONDEPE/FIDEM, 2016).

A gênese desse Complexo Industrial Portuário remonta à década de 1970 do século passado, sendo consolidado enquanto empresa, fundamentalmente, entre os anos de 1978 e 1983; e tornando-se efetivamente um complexo em meados do século XXI. Para pensar o CIPS em sua totalidade é preciso revisitar o contexto histórico econômico, no qual globalmente o capitalismo avançado vinha praticando a política de expansão do capital através da exploração dos novos territórios, sobretudo tecendo teias de interesses com os países subdesenvolvidos assentados em estratégias ligadas, em especial, à indústria de transporte e de comunicação (Gomes; Albuquerque, 2015).

É nesse decurso que "Suape se insere no conjunto das determinações advindas da complexa divisão internacional do trabalho" (Gomes; Albuquerque, 2015, p. 07), baseado, sobretudo, na reorganização e redefinição espaciais, em termos funcionais, capitaneadas pelas organizações e/ou empresas monopolistas, contribuindo em grande medida às novas demandas de ampliação do capital, para fins de extração e maior acumulação de mais-valia nesse contexto histórico.

Nessa via estratégica, o CIPS se configura como uma ferramenta indispensável à comunicação e transporte de mercadorias, na medida em que torna possível a reconfiguração - de um patamar agrícola para o industrial, tecnologicamente mais avançado - espacial, tornando-se a solução dos latifundiários sucroalcooleiros que vivenciavam a crise dessa atividade nesse contexto histórico.

Fator que faz do CIPS especialmente atrativo aos novos empreendimentos (estaleiros, refinarias, dentre outras organizações industriais e de serviços), que atualmente integram o complexo; por sua vez são controlados por empresas estrangeiras, na condição de detentoras da tecnologia ou do know-how, consequentemente, possibilitando-as "obter maiores taxas de lucro através das estratégias de dominação dos territórios para a acumulação de capital” (Gomes; Albuquerque, 2015, p. 9).

É indispensável pontuar que em relação ao seu aspecto de dominação e, em particular "à sua determinação mais profunda, o sistema do capital é orientado para a expansão e movido pela acumulação” (Mészáros, 2011, p. 100). Adicionalmente, essa peculiaridade se apresenta, dentre outras, através da política na figura do Estado, ou ainda sob "a forma da instituição 
do controle político total” (p. 99). Por sua vez, (o Estado) sendo indissociável e exercendo uma relação de complementaridade à sociometabolização do capital (Mészáros, 2011; Paniago, 2005).

Para o caso do CIPS, isto é materializado, especialmente por meio dos "pactos da pequena política no plano do governo estadual e local, até mesmo interferindo na ampliação da Região Metropolitana, com a inserção do município de Ipojuca em 1994” (Gomes; Albuquerque, 2015, p. 9), que juntamente com a Cidade do Cabo de Santo Agostinho, delimitam geograficamente o CIPS. Em nível de exemplificação, o Estado investe em construções e restauração de vias (rodoviárias, aquaviárias e ferroviárias), sob a égide da melhoria da mobilidade urbana e, consecutivamente, dos indicadores sociais. Todavia esses argumentos caem por terra quando "se percebe todo um direcionamento do Estado para a instalação e permanência das empresas, sem que haja a intenção de redução das desigualdades através de investimentos deste porte, contraditoriamente ampliando os problemas sociais" (Gomes; Albuquerque, 2015, p. 17). No fim das contas, vê-se materializado projetos dessa magnitude consubstanciando aumento no fluxo de mercadorias.

Concomitantemente, constata-se a participação direta do CIPS como vetor imobiliário. Para que as reconfigurações espaciais se efetivassem resultantes do processo de instalação e ampliação do CIPS, em termos funcionais, foi necessária uma demanda de contingente populacional elevado, aspecto notadamente percebido pelo aumento demográfico, principalmente nas cidades do Ipojuca e Cabo de Santo Agostinho e na Região Metropolitana do Recife. Fato que, por sua vez, engendrou processos relacionados à especulação imobiliária pela via da elevação dos preços de imóveis e de aluguéis, bem como pela:

[...] forte atração por novos empreendimentos habitacionais privados, expressando e consolidando uma nova forma de intervenção no território através da implantação das chamadas "Cidades Planejadas", que de uma maneira geral, são planejadas sem nenhuma intervenção do poder público municipal e sem a participação da sociedade local nos processos decisórios. Nos dois municípios em análise observa-se a promoção de pelo menos quatro grandes empreendimentos com essas características, sendo eles: Reserva do Paiva - Cabo de Santo Agostinho, Convida Suape - Cabo de Santo Agostinho, Engenho Trapiche Ipojuca - Ipojuca, Reserva Ipojuca - Ipojuca (Medeiros et al., 2014, p. 76). 
Essa nova dinâmica habitacional é contraditória na medida em que a população residente e/ou local não consegue acompanhar financeiramente o custo de vida instalado, consequentemente, ocasionando o seu empobrecimento e aumentando as desigualdades sociais, sobretudo, pela ausência de planejamento urbano por parte do Estado (Medeiros et al., 2014).

Constata-se ainda que o surgimento desses novos empreendimentos, como no caso da Reserva do Paiva, está intimamente correlacionado com a apropriação da natureza e privatização dos espaços públicos "de acesso à praia, por exemplo, ou até mesmo na apropriação sob a égide da parceria público-privada de reservas florestais e manguezais. Esses elementos de ordem natural passam a integrar a mercadoria imobiliária através da estética anunciada na publicidade" (Barbosa; Gomes, 2016, p. 344). Em razão disso, Gomes e Albuquerque (2015, p. 23) assinalam que:

[...] a instalação de grandes complexos industriais, com respaldo do Estado que se insere na lógica de concorrência entre cidades para a instalação desses empreendimentos na maioria dos casos, formados por capital estrangeiros, dando todas as condições possíveis, em troca de vagas de emprego, que, no entanto, não são suficientes para que promova do desenvolvimento local. E essa lógica tem se perpetuado de maneira cada vez mais perversa, articulada pelos agentes hegemônicos, desconsiderando o impacto na vida cotidiana de maior parte da população.

Pode-se inferir que há, sem dúvida, um protagonismo das chamadas parcerias público-privadas, em que o Estado atua num contexto de aliança aos imperativos dos agentes privados. Essa assertiva é revelada por Barbosa e Gomes (2016) - ao examinar como se dão as contradições acerca da Reserva do Paiva - ao afirmarem o protagonismo do poder público no "processo de regulação e de legitimação das iniciativas de proprietários fundiários, incorporadores, construtores, dentre outros que igualmente interferem na produção do espaço da cidade e logram os frutos financeiros da acumulação urbana.” (Barbosa; Gomes, 2016, p. 344).

Toda essa mediação faz emergir o caráter de classe do Estado no que se refere à adoção de políticas públicas, na medida em que favorece uma lógica estrutural e ao mesmo tempo superestrutural de agentes hegemônicos, um movimento que pela via de acumulação pelo capital estrangeiro - das multinacionais - engendra processos ligados à 
precarização do trabalho, logo, desigualdades sociais e em última análise, degradações ambientais. Desmistificando factualmente o discurso político socioambiental, apoiado no interesse social e de motivações ambientais (Lessa, 2013; Gomes; Albuquerque, 2015).

Em que pese à questão ambiental, fundamentalmente vinculada ao discurso socioambiental contemporâneo, consubstanciada pela presença do Estado como mediador - através das políticas públicas sociais e ambientais -, se torna em grande medida o que o Sergio Lessa (2013) vai chamar de "o falso social necessário", objetivando tão somente justificar um status quo, uma vez que efetivamente, para o objeto deste estudo, o CIPS, o que se constata materializado, histórico e atual são degradações à natureza em longa escala.

Em seu ensaio, Mészáros (2011) vai iluminar essa discussão ao afirmar que o Capital, no que se refere ao seu caráter particular e totalizador (ou seja, para que ocorra a expansão e acumulação), este tem o imperativo ambiental - sob a forma dos movimentos ambientalistas, "partido verde", Agenda 2030 para o desenvolvimento sustentável etc., apesar de inconteste e urgente - como parte "não integrável” à sua lógica estrutural, portanto antagônico. Diante disso, apesar de desconfortável, nos parece coerente a afirmação de que o imperativo ambiental seja inviável dentro da estrutura do Capital, por se revelar "inadministrável em virtude das correspondentes restrições necessárias aos processos de produção em vigor exigidas para sua implementação.” (Mészáros, 2011, p. 100).

No contexto do CIPS, essa dinâmica não integrável da natureza à dinâmica estrutural do Capital, a priori, é identificada ainda nos primórdios de sua implantação e ampliação (décadas de 1970 e 1980), à medida que foi "necessária" a desapropriação de 22 engenhos - o que corresponde a 13,5 mil hectares e 4 ilhas. Em razão disso, emergindo processos de desterritorialização por despossessão; impactos ambientais a ecossistemas de mata atlântica, de manguezais e áreas estuarinas, além da contaminação dos rios Ipojuca, Merepe, Massangana e Tatuoca que se constituem como importantes fontes de recursos às populações locais historicamente (Medeiros et al., 2014; Gomes; Albuquerque, 2015).

Na transição do século XX para o XXI, o movimento não altera seu curso; pelo contrário, é acelerado. Tem-se materializada, por meio de políticas públicas, concessões e/ou leis autorizativas (leia-se capitalista, 
97\% destinadas ao CIPS) em larga escala para supressão de Áreas de Preservação Permanente (APP); em especial aos manguezais, objetivando a instalação e ampliação de novos empreendimentos (principalmente, os Estaleiros Atlântico Sul (EAS) e Vard Promar, Refinaria Abreu e Lima (RNEST), Petroquímica Suape etc.) (Coelho; Tavares, 2013).

Dados que comprovam a (des)legitimação das leis ambientais, em sua totalidade - que reiteramos, supunham serem equânimes -, presentes mesmo antes da pedra fundamental do CIPS ser lançada em 1974. Tem-se como exemplo, os códigos florestais de 1934, 1965 e 2012 (MMA, 2011). A contradição é acentuada à medida que as leis citadas são violadas através do Estado com a criação de leis de ordem econômica sob argumentos de exceção, ${ }^{2} \operatorname{logo}$, nada coerentes. Convém não ser suficientemente aceitável que em áreas cuja característica e importância são vedadas sua modificação e exploração econômica (Cavedon, 2016) estejam sendo suprimidas justamente por práticas dessa natureza.

Destacam-se ainda as restrições ambientais previstas no Plano Diretor e/ou inventario ecológico, que, pouco a pouco perdeu espaço, e "que não se reconhece atualmente realizado” (Gomes; Albuquerque, 2015, p. 03). Desta forma, o desinderatum socioambiental está longe de uma efetividade objetiva, ao contrário disto, ele se converte na contemporaneidade, como apenas mais um "falso social necessário" à plena sociometabolização do capital (Mészáros, 2011).

No fim das contas, o que se percebe é que os caminhos sinuosos de Suape estão sendo (re)direcionados a uma lógica, um movimento que "na atualidade foi incorporado e devidamente apropriado nas dimensões do capital que lhe conduz em trajetória bem definida [...]" (Gomes; Albuquerque, 2015, p. 02), que aparentemente, nada tem que ver com o discurso do "Estado de bem estar socioambiental".

\section{Suape e o (Des)Integrativo Imperativo Ambiental}

A questão ambiental, como um desinderatum sustentável para as atividades desempenhadas pela humanidade, é inegavelmente urgente. Nesse sentido, historicamente as leis ambientais desempenham (ou deveriam) um papel fundamental, no sentido de conter as atividades capitalistas de reprodução potencializadoras de impactos ao ambiente. Quer numa visão unicamente ambientalista, quer numa perspectiva mais holística 
(socioambiental), ambas as miradas são legitimadas pelos não poucos atuais índices de degradações impostos à natureza em escala planetária.

Todavia a relação entre Capital, Estado e Natureza, a partida caminha numa visão (des)integradora, pela qual os dois primeiros exercem funções complementares (de integração) por meio de práticas de exploração em relação ao último (de desintegração). Logo, clarifica (porém não justifica) como o Estado - enquanto figura institucional política - atua no contexto em que reiteradamente favorece processos e/ou atividades para expansão e acumulação de capital.

Nesse sentido, doravante são dialeticamente discorridas algumas considerações acerca do imperativo ambiental, através das leis institucionalmente legitimadas, todavia, para o caso do CIPS, sendo a todo tempo negligenciadas, também por meio de criação de leis de ordem capitalista legitimadas pelo Estado, logo, fazendo emergir o seu caráter de classe - tendo em conta os agentes hegemônicos privados beneficiados em detrimento de políticas sociais e ambientais.

Para o CIPS, são tecidas considerações sobre as leis destinadas às Áreas de Preservação Permanente (APP) e Unidades de Conservação (UC), legitimadas no âmbito federal e no estado de Pernambuco, e que atualmente delimitam a cidade do Ipojuca e Cabo de Santo Agostinho; e, consecutivamente inseridas em seu contexto territorial. Nessa ótica, as APP são pelo art. $1^{\circ}$, $2^{\circ}$, inciso II da Lei federal 4.771/65, o Código Florestal e seus decretos posteriores como (Câmara Federal, 1965):

$\S 2^{\circ}$. Área de Preservação Permanente: área protegida nos termos dos arts. $2^{\circ}$ e $3^{\circ}$ desta Lei, coberta ou não por vegetação nativa, com a função ambiental de preservar os recursos hídricos, a paisagem, a estabilidade geológica, a biodiversidade, o fluxo gênico de fauna e flora, proteger o solo e assegurar o bem-estar das populações humanas.

Ainda no âmbito federal, são consideradas como Áreas de Preservação Permanente nos termos da Resolução CONAMA n ${ }^{0}$ 303, de 20 de março de 2002 (MMA, 2011), em seu Art. 3: "Constitui Área de Preservação Permanente a área situada": X - "em manguezal, em toda a sua extensão".

Quanto à esfera estadual, a Lei Estadual n 11.206, de 31 de março de 1995, dispõe sobre a Política Florestal do Estado de Pernambuco e dá outras providências (Pernambuco, 1995): Art. 9. "Consideram-se de preservação permanente, para efeito desta Lei, as florestas e demais formas 
de vegetação natural situadas": VII - "nos manguezais, em toda a sua extensão".

Depreende-se do anterior, o fato de essas áreas não atuarem apenas em âmbito preservacionista da flora e fauna, mas elas exercem ou deveriam exercer funções bem mais abrangentes, em especial, aquelas correlacionadas à proteção dos recursos hídricos e o de conceber o bemestar das populações humanas (MMA, 2011).

Todavia, o discurso não segue a regra, tampouco vem se materializando. Ainda na década de 80, Braga et al. (1989) evidenciam, em 1974, a presença de 2.874 hectares de APP em Suape. Passados quatorze anos (1988), os autores chamam a atenção para o fato de que "considerando-se apenas a área de jurisdição do Complexo Industrial e Portuário, dos 1.005 hectares de mangue existentes dentro dos seus limites, 60\% já estão degradados” (Braga et al., 1989, p. 15), afetando principalmente o "manguezal do rio Tatuoca e parcialmente nos rios Massangana e Ipojuca” (p. 15).

É importante ressaltar que já se tinha em vigor o Código Florestal de 1965. Na atualidade, entre 2007 e 2015, foi autorizada a supressão de 659 ha de APP, todas envolvidas na implantação e ampliação dos megaempreendimentos (estaleiro, refinaria etc.), quando sua concepção é explicitamente vedada para as atividades com fins econômicos e potencialmente impactantes (Coelho; Tavares, 2013).

De outro lado, há as Unidades de Conservação cujo regime jurídico é bem mais denso, cabendo aos governos das esferas federal, estadual e municipal, a sua gestão. São regidas, sobretudo, pelo Sistema Nacional de Unidades de Conservação - SNUC, Lei no 9.985/00 e seus decretos posteriores $\mathrm{n}^{\circ}$ 4.340/02 e o $\mathrm{n}^{0}$ 5.746/06 (MMA, 2011). Para o estado de Pernambuco, encontra-se a Lei $\mathrm{n}^{0} 13.778 / 09$ dispondo sobre o sistema Estadual de Unidades de Conservação da Natureza - SEUC (CPRH, 2017).

No que se refere ao conceito e objetivos, as UC estão divididas em dois grupos: de proteção integral e de uso sustentável, diferenciando-se "quanto à forma de proteção e usos permitidos: aquelas que precisam de maiores cuidados, pela sua fragilidade e particularidades, e aquelas que podem ser utilizadas de forma sustentável e conservadas ao mesmo tempo". (Disponível em: <http://www.mma.gov.br/areas-protegidas/ sistema-nacional-de-ucs-snuc $>$ ). 
Para a categoria proteção integral implica a "manutenção dos ecossistemas livres de alterações causadas por interferência humana, admitido apenas o uso indireto dos seus atributos natural”, tendo no art. $7^{\circ}$, do SNUC: $\S 1^{\circ} \mathrm{O}$ objetivo básico das Unidades de Proteção Integral é preservar a natureza, sendo admitido apenas o uso indireto dos seus recursos naturais, com exceção dos casos previstos nesta Lei.

Já para o caso das UCs de uso de sustentável, são aquelas em que: $\S 2^{\circ} \mathrm{O}$ objetivo básico das Unidades de Uso Sustentável é compatibilizar a conservação da natureza com o uso sustentável de parcela dos seus recursos naturais.

Na atualidade, o CIPS contempla dentro de seus limites territoriais 4 UC. Desse total, 3 são categorizadas como de proteção integral: os Parques Estaduais de Duas Lagoas, Mata do Zumbi e a Estação Ecológica de Bita e Utinga;. e 1 de uso sustentável (criada em 2014), a Área de Relevante Interesse Ecológico (ARIE) dos Rios Ipojuca-Merepe, situada no município de Ipojuca, com 1.488,81 hectares de área de ecossistemas Manguezal e Restinga, resultante de um processo de compensação (Suape, 2017).

Sobre essas UC, são questionáveis a criação da Estação de Bita e Utinga (2012), cuja aplicabilidade convive com o argumento protecionista (de preservação) ao mesmo tempo em que prevê a obrigatoriedade de saída ${ }^{3}$ (em muitos casos, de forma abusiva e com o uso de violência física) das populações locais. De outra parte, tem-se a ARIE, especificamente, em relação ao critério utilizado para sua criação, na medida em que os manguezais (APP) já são protegidos por lei federal, logo, não necessitando tornar UC, ou seja, “cria-se proteção para o que já é protegido por lei” (Coelho; Tavares, 2013). Deste ponto de vista, depreende-se o "negligenciamento" dos técnicos - no estado de Pernambuco, de competência da Agência Estadual de Meio Ambiente (CPRH) - para com as regras compensatórias previstas na Lei ${ }^{\circ} 11.206 / 1995$, art. $8^{\circ}$ da Política Florestal do Estado (Pernambuco, 1995):

$\S 2^{\circ}$ A supressão da vegetação de que trata este artigo deverá, preferencialmente, ser compensada com a preservação ou recuperação de ecossistema semelhante, sendo no mínimo correspondente à área degradada, e que garanta a evolução e a ocorrência dos processos ecológicos, anteriormente à conclusão da obra. (Redação dada pelo art. $1^{\circ}$ da Lei $\mathrm{n}^{\circ} 15.652$, de 24 de novembro de 2015.) 
Ressalta-se, ainda, o uso indiscriminado da lei de compensação como instrumento de regularização do direito de degradar. Uma contradição legitimada novamente pelos técnicos que usurpam o Art. 10 da Lei Federal $n^{\circ}$ 6938/81, que dispõe sobre a Política Nacional de Meio Ambiente. Segundo Coelho e Tavares (2013), o que ocorre no caso do CIPS é a venda do direito de poluir na medida em que "A compensação ambiental busca um ajustamento das atividades discordantes e não, obviamente, viabilizar os "desejos poluidores" do empreendedor" (Coelho; Tavares, 2013, p. 6). Questiona-se o destino dado pelo Estado do montante recebido, aproximadamente 215 milhões de reais, oriundos de licenciamento ambiental (EIA/RIMA), por meio da CPRH, para construção e ampliação de megaempreendimentos que integram o CIPS, com destaque para o EAS, RNEST, Estaleiro Promar e Petroquímica Suape entre os anos de 2005 e 2016 (CPRH, 2017).

Medidas permissíveis que fazem emergir, na Ilha de Tatuoca, a realização econômica - através da instalação e ampliação dos Estaleiros Atlântico Sul e Vard Promar - diretamente correlacionada à supressão de manguezais e desapropriações de várias famílias (Costa, 2016). Some-se a isto, os mais de 50 mil trabalhadores destituídos de seus postos de trabalho entre 2014 e 2016 (JC, 2015; Costa, 2016) -, um movimento que nada tem que ver com o objetivo previsto na lei do SNUC: "Proteger os recursos naturais necessários à subsistência de populações tradicionais, respeitando e valorizando seu conhecimento e sua cultura e promovendo-as social e economicamente". (Disponível em: <http://www.mma.gov.br/ areas-protegidas/sistema-nacional-de-ucs-snuc $>$ ).

Por todo o exposto, a retórica ambiental utilizada pelo Estado, no que se refere às atividades no CIPS, se apresenta contraditória ao que dispõem as leis ambientais mencionadas. Autorizando a assertiva de que a questão ambiental converte-se em não integrável à lógica contemporânea de desenvolvimento econômico, logo, configurando a relação harmônica entre o social, o ambiental e o econômico não factual. Caminhamos, como visto, no pensamento dos vários autores(as) citados(as), centrados na análise crítica em torno de políticas públicas capitalistas, que factualmente continuam a subverter o direito tanto da conservação/preservação da flora, fauna e dos recursos hídricos, bem como das populações locais, desmistificando o que na atualidade tem-se como "Estado de bem-estar socioambiental". 
Ademais, conclui-se que o que se vê no discurso socioambiental histórico e atual, sob a forma de uma ou outra adjetivação (economia verde, desenvolvimento sustentável, sustentabilidade etc., todos estes presentes no site Suape), são na verdade uma forma de adequação do Capital para que possa prosseguir com a sua dinâmica sociometabólica (para citar Mészáros, 2011) - para o CIPS, essa característica pode ser constatada pela utilização do marketing ${ }^{4}$ ambiental. Esses ajustes, diz o autor, consistem em "contornar os obstáculos e resistências encontrados, sempre que ele fosse incapaz de demoli-los" (Mészáros, 2011, p. 100), tendo em vista que o sistema do capital não submete-se ao "controle adequado duradouro ou a uma autorrestrição racional” (Mészáros, 2011, p. 100).

\section{Considerações Finais}

O discurso ambiental adotado na contemporaneidade, como visto, mais vela ${ }^{5}$ do que clarifica a realidade. A materialidade acerca da atuação do Estado através do discurso ambiental, em relação ao Complexo Industrial Portuário de Suape, se apresenta contraditória na medida em que, por um lado, aparentemente o empreendimento tem suas atividades regradas por políticas públicas de desenvolvimento aliadas a imperativos de sustentabilidade; por outro, historicamente vem atuando num contexto de legitimação - também através de políticas públicas - de atividades estritamente econômicas, portanto, inserido numa lógica de exploração e apropriação dessa natureza que teoricamente se almejaria preservar.

Os caminhos sinuosos de Suape estão cada vez direcionados para as vias de acumulação do capital estrangeiro. Através de políticas expansionistas promovidas em grande medida pelas chamadas parcerias público-privadas, o Estado neoliberal se converte no mais efetivo elo das transnacionais no seu processo perverso de exploração socioambiental desse território. A priori, a gênese deste Complexo portuário é intencionalmente pensada para a salvação da economia pernambucana a todo custo, não importando as desapropriações das várias famílias e supressões de vastíssimas áreas de vegetação. A posteriori, o movimento contemporâneo é acelerado dentro dessa lógica, uma vez que as políticas públicas autorizativas de crescimento econômico para instalação e ampliação de empresas estão diretamente correlacionadas à desterritorializações e déficit de qualidade de vida (altos índices de desemprego, aumento do custo de vida) para as populações locais. 
Tudo isso sob a égide contraditória do interesse social e da geração de emprego e renda que, ao nosso juízo, tem se materializado com a precarização do trabalho, constituindo-se assim como "um falso social necessário" a serviço da contínua afirmação do status quo evidenciado. Não obstante, junto ao Estado, vê-se objetivada outra característica de atuação desse tipo de megaempreendimento, o capital privado que se sociometaboliza pela via da especulação imobiliária com a construção de condomínios fechados de alto luxo, notadamente atingindo um público alvo elitizado. Contexto que faz emergir processos de favelização ao seu entorno e triviais exemplos de apropriação e artificialização da natureza.

Em alguma medida, os resultados apontam o aspecto integrativo entre Estado e Capital. Para o caso do CIPS, vem se manifestando a partir dos agentes políticos e econômicos, em que o primeiro - nas esferas municipal, estadual e federal - atua num contexto de incentivos fiscais e ambientais, que autorizam o segundo a realizar a exploração dos recursos naturais; uma forma de legitimação exploratória obtida através de um movimento discursal, aparentemente regrado por práticas sustentáveis, mas que em verdade atuam numa trama desintegrativa ${ }^{6}$ da natureza e das populações envolvidas que, respectivamente, conjectura-se preservar e conceber melhores condições de vida. Portanto, priorizando os agentes econômicos e os ideários governamentais de crescimento e expansão, com o fim de obter o consenso social. Em síntese, o discurso socioambiental destinado a justificar um status quo de cuja consequência, nesse contexto, é precisamente a desintegração da natureza.

\section{Notas}

1 Considera-se como discurso ambiental todas as formas de abordagem pelas quais alguns agentes se utilizam da questão ambiental como um meio de promover, em especial, a noção de desenvolvimento sustentável e, por conseguinte, de sustentabilidade em suas atividades e/ou práticas. Para Acselrad (1999), essas ideias são verdadeiramente mais uma maneira de alienação - o que o autor vai chamar de "causalidade teleológica" (ACSELRAD, 1999, p. 81) - pela qual os agentes hegemônicos (públicos e privados) tendem a adequar-se, objetivando dar continuidade aos seus projetos de desenvolvimento econômico. Tem-se como exemplo o "esverdeamento de megaprojetos industriais" cujos intentos, aparentemente, estão centrados em desenvolver socioambientalmente certos territórios, mas sua materialidade é contraditória a esses propósitos.

2 Nas leis supramencionadas, os projetos potencialmente impactantes que exigirem a supressão de APPs, apenas poderão ser autorizados sob duas exceções: o interesse social 
e a utilidade pública. É nesse víeis que o Estado de Pernambuco vem atuando junto (e, em parceria) aos órgãos ambientais, em especial, a CPRH.

30 plano Diretor, Suape 2030, prevê a saída de todos os munícipes locais dentro de UCs, sob o argumento de preservação ambiental. Para se ter ideia, os estudos produzidos pela CPRH demonstram que o gasto médio para a criação de uma UC gira em torno de $R \$ 3,5$ milhões. Na UC supramencionada já foram gastos cerca de R\$ 46 milhões, prioritariamente, para retirada de populações tradicionais. Os relatos informais de moradores e de pesquisas recentes demonstram que se trata, fundamentalmente, de ordenamento territorial e não de preservação ambiental (Araújo, 2016).

4 A utilização do marketing ambiental ou marketing verde que, aparentemente, pressupõe a ideia de que seja possível criar riquezas com a diminuição de impactos ambientais negativos, converte-se na atualidade em mais uma ferramenta mercadológica utilizada para explorar os recursos ambientais (Gonzaga, 2005).

5 No ensaio sobre o uso da palavra desenvolvimento, Santos et al. (2012) fazem várias advertências ao afirmar que a depender de quem fala e das intencionalidades explícitas e implícitas (em sua maioria), elas podem fazerem-nos ser, e outras vezes não ser. Para o caso do discurso ambiental, em muitos casos, a adjetivação sustentável adicionada a palavra desenvolvimento pode apenas ficar no campo teórico e/ou ainda servir como argumento legitimador de atividades exploratórias.

6 Nesse contexto o "sólido e duradouro" pretendido pelas legislações ambientais (criação de APP e UC), dentre outras noções de sustentabilidade, não se convertem em realidade, uma vez que a visão de progresso e de crescimento contemporâneos estão essencialmente atrelados a processos de transformação cíclicos - destruir para construir. Logo, constituem tão-somente sua autodestruição, em outras palavras, para citar novamente Marshall Berman (1986, p. 94), "dizer que nossa sociedade está caindo aos pedaços é apenas dizer que ela está viva e em forma".

\section{Agradecimentos}

O presente artigo é fruto de investigações fomentadas pelo Programa de Pós-Graduação em Desenvolvimento e Meio Ambiente - PRODEMA (UFPE) e pelo Grupo de Pesquisa, Sociedade e Natureza Nexus (UFPE).

\section{Referências}

ACSELRAD, H. Discursos da Sustentabilidade Urbana. Revista B. Estudos Urbanos e Regionais, São Paulo, n. 1, p. 79-90, maio 1999. http://dx.doi. org/10.22296/2317-1529.1999n1p79

ARAÚJO, M. P. A Implantação da Unidade de Conservação Estação Ecológica Bita e Utinga da Refinaria Abreu e Lima, no Porto de Suape - PE. 2016. $121 \mathrm{f}$. Dissertação (Programa de Mestrado Profissional em Gestão do Desenvolvimento Local Sustentável) - Faculdade de Ciências da Administração de Pernambuco, Universidade de Pernambuco, Recife, 2016. 
BARBOSA, A. G.; GOMES, E. T. A. Reflexão sobre o papel do setor imobiliário na acumulação urbana. Revista Soc. \& Nat., Uberlândia, v. 28, n. 3, p. 333-346, set./dez. 2016. http://dx.doi.org/10.1590/1982-451320160301

BERMAN, M. Tudo Que é Sólido Desmancha no Ar: A Aventura da Modernidade. Tradução de Calos Felipe Moisés e Ana Maria L. Ioriatti. São Paulo: Companhia das Letras, 1986.

BRAGA, R. A. P. et. al. Impactos ambientais sobre o manguezal de Suape - PE. Acta Botanica Brasilica, Belo Horizonte, v. 3, n. 2, supl. 1, Feira de Santana, 1989. http://dx.doi.org/10.1590/S0102-33061989000300003

CAVEDON, F. et al. Regime jurídico das áreas de preservação permanente e desenvolvimento econômico: conciliação ou flexibilização? Ambiente Legal. São Paulo, 2016. Disponível em: <http://ambientallegal.com.br/>. Acesso em 2 jul. 2017.

CÂMARA FEDERAL. Legislação Informatizada - Lei $n^{\circ}$ 4.771, de 15 de setembro de 1965 - Publicação Original. Disponível em: <http://www2.camara.leg.br/ legin/fed/lei/1960-1969/lei-4771-15-setembro-1965-369026-publicacaooriginal-1pl.html>. Acesso em: 13 maio 2017.

COELHO JR., C.; TAVARES, P. F. Uma Abordagem sobre a Perda de Áreas de Manguezal pelas Leis Autorizativas no Estado de Pernambuco. In: IV Congresso Brasileiro de Gestão Ambiental, 2013, Salvador. Anais... Salvador: IBEAS Instituto Brasileiro de Estudos Ambientais, 2013.

CONDEPE/FIDEM. Agência Estadual de Planejamento e Pesquisas de Pernambuco. Caracterização do Território de Suape. 2016. Disponível em: <http://200.238.107.83/web/condepe-fidem/caracterizacao-do-territorio>. Acesso em: 15 fev. 2017.

COSTA, H. S. Suape: promessas não cumpridas. Fórum Suape, Informativo Mensal do Fórum Suape Espaço Socioambiental, n. 04, out. 2016. Disponível em: <http://fase.org.br/wp-content/uploads/2016/10/JORNAL-FORUM-SOCIALSUAPE-4.pdf>. Acesso em: 10 jul. 2017.

CPRH. Agência Estadual de Meio Ambiente. Descrição das Unidades de Conservação. Disponível em: <http://www.cprh.pe.gov.br/Unidades_de_ Conservacao/descricao_das_unidades/41788\%3B48981\%3B5001\%3B0\% $\overline{3}$ B0. asp>. Acesso em: 13 jul. $201 \overline{7}$.

CPRH, et al. Proposta para Criação de Unidades de Conservação no Estuário dos Rios Ipojuca-Merepe. Recife: CPRH, 2014. p. 33. Disponível em: <http://www. cprh.pe.gov.br/ARQUIVOS_ANEXO/Proposta_IpojucaMerepe_Versao_Final. pdf $>$. Acesso em: 13 jun. $20 \overline{17}$.

GOMES, E. T. A.; ALBUQUERQUE, M. Z. A. Nova dinâmica urbana na Região Metropolitana do Recife: O Complexo Industrial Portuário de Suape como (des) articulador de escalas. In: XIV Simpósio de Geografia Urbana: Perspectivas e abordagens da Geografia urbana no século XXI, 2015, Fortaleza. Anais... Fortaleza, 2015. p. 01-26.

GONZAGA, C. A. M. Marketing Verde de Produtos Florestais: Teoria e Prática. Revista FLORESTA, Curitiba, PR, v. 35, n. 2, maio/ago. 2005. http://dx.doi. org/10.5380/rf.v35i2.4623 
HOWE, I. Introduction. In: HARRINGTON, M. The other America - povert in the United States. Scribder: Nova York, 1993.

JC. Documento Suape 2015: depois da euforia, contam-se os prejuízos. 2015. Disponível em: <http:/especiais.jconline.ne10.uol.com.br/documento-suape-2015/>. Acesso em: 10 fev. 2017.

LESSA, S. Capital e Estado de Bem-estar: O caráter de Classe das políticas públicas. São Paulo: Instituto Lukács, 2013.

MEDEIROS, M. C. et al. 'Os impactos do Complexo Industrial Portuário de Suape CIPS nos municípios do Cabo e Ipojuca. ARCHITECTON - Revista de Arquitetura e Urbanismo, v. 04, n. 07, p. 67-80, 2014. Disponível em: <http://www.faculdadedamas. edu.br/revistafd/index.php/arquitetura/article/view/299/285>. Acesso em: 10 jun. 2017.

MÉSZÁROS, I. [1930]. Para além do capital: rumo a uma teoria da transição. Tradução Paulo Cezar Castanheira, Sérgio Lessa. 1. ed. São Paulo: Boitempo, 2011.

MMA. Ministério do Meio Ambiente. Áreas de Preservação Permanente e Unidades de Conservação \& Áreas de Risco. O que uma coisa tem a ver com a outra? In: SCHÄFFER, W. B. et al. Relatório de Inspeção da área atingida pela tragédia das chuvas na Região Serrana do Rio de Janeiro. Brasília: MMA, 2011. (Série Biodiversidade, 41).

- Ministério do Meio Ambiente. Sistema Nacional de Unidades Conservação-SNUC. Disponível em: < http://www.mma.gov.br/areas-protegidas/ sistema-nacional-de-ucs-snuc >. Acesso em: 15 jun. 2017.

PANIAGO, M. C. S. Estado e Capital, em Mészáros: relação de autonomia ou de complemento? In: II Jornada Internacional de Políticas Públicas, 2005, São Luís, Maranhão. Anais... São Luís, MA: UFAL, 2005. Disponível em: <http://www. joinpp.ufma.br/jornadas/joinppIII/html/Trabalhos2/maria_Cristina_Soares_ Paniago.pdf>. Acesso em: 13 fev. 2017.

PERNAMBUCO (Estado). Lei n ${ }^{\circ} 11.206$, de 31 de março de 1995. Política Florestal do Estado de Pernambuco e dá outras providências. Disponível em: <www.cprh. pe.gov.br/downloads/Lei-11206.doc>. Acesso em: 10 fev. 2017.

SANTOS, L. S. et al. Desenvolvimento: Um Conceito Multidimensional. DRd - Desenvolvimento Regional em debate, ano 2, n. 1, jul. 2012. Disponível em: <http://recipp.ipp.pt/handle/10400.22/1858>. Acesso em: 10 mar. 2017.

SUAPE. Complexo Industrial Portuário. Desenvolvimento com Sustentabilidade. Disponível em: <http://www.suape.pe.gov.br/pt/meio-ambiente/ desenvolvimento-com-sustentabilidade>. Acesso em: 15 abr. 2017.

Complexo Industrial Portuário. Gestão Ambiental: Unidades de Conservação. Disponível em: <http://www.suape.pe.gov.br/pt/meio-ambiente/ gestao-ambiental/unidades-de-conservacao>. Acesso em: 10 fev. 2017. 
Dweison Nunes Souza da Silva - Graduado em Ciências Biológicas pela FAMASUL. Mestre em Desenvolvimento e Meio Ambiente pela Universidade Federal de Pernambuco, com período sanduíche na Universidad Pontificia Bolivariana - UPB, Colômbia. Atualmente exerce a função de professor efetivo vinculado à Secretaria de Educação do Estado de Pernambuco. ORCID: https://orcid.org/0000-0002-4720-4022.

Edvânia Torres Aguiar Gomes - Graduada em Ciências Geográficas pela Universidade Católica de Pernambuco. Mestra em Geografia pela Universidade Federal de Pernambuco e doutora em Geografia pela Universidade de São Paulo. Pós-doutorado na Universität Leipzig, Alemanha. Estágio no IFL - Leipzig. Atualmente é professora titular da Universidade Federal de Pernambuco. ORCID: https://orcid.org/0000-0002-0865-4805.

\section{Contribuições dos autores}

O artigo é constituído de colaborações conjuntas. Dweison Nunes Souza Silva contribuiu na construção e na elaboração dos referenciais teóricos, metodológicos e no desenvolvimento do artigo de uma maneira geral. Edvânia Torres Aguiar contribuiu para as discussões e reflexões para melhor interpretação do referencial teórico e para a elaboração do texto do final; assim como das traduções.

Recebido para publicação em 12 de outubro de 2017 Aceito para publicação em 28 de dezembro de 2017 